\title{
Regularity of Uterine Contraction
}

National Cancer Institute

\section{Source}

National Cancer Institute. Regularity of Uterine Contraction. NCI Thesaurus. Code C92868.

The nature and pattern of occurrence for the uterine contractions during labor. 